\title{
Electrophysiological and histological observations on peripheral nerves in acrylamide poisoning in man
}

\author{
PAMELA M. FULLERTON \\ From the Institute of Clinical Research, The Middlesex Hospital, London, and \\ the Medical Research Council Toxicology Unit, Carshalton, Surrey
}

In 1967 Garland and Patterson described six patients who developed peripheral neuropathy and ataxia after exposure to acrylamide during their work. The neuropathy involved both motor and sensory fibres. Ataxia was out of proportion to the sensory loss and was thought to indicate brain-stem as well as peripheral nerve involvement by the poison. Electrophysiological studies of peripheral nerve conduction have been carried out on three of these patients and sural nerve biopsies on two of them. The findings form the basis of the present report.

A few other cases of industrial poisoning by acrylamide have been recorded. Ten cases were described by Fujita, Shibata, Kato, Amomi, Itomi, Sujuki, Nakajawa, and Tamahashi in 1960 from Japan, and a further case has been reported from Canada by Auld and Bedwell (1967). The clinical features of these patients were similar to those described by Garland and Patterson (1967).

\section{METHODS}

ELECTROPHYSIOLOGY Motor nerve conduction velocity was measured using standard techniques, muscle action potentials being recorded through a concentric needle electrode inserted into one of the small muscles of the hand or foot (Thomas, Sears, and Gilliatt, 1959).

Sensory nerve action potentials were recorded through saddle electrodes over the median or ulnar nerves at the wrist as described by Dawson (1956).

HISTOLOGY Biopsies of the sural nerve were taken at the level of the lateral malleolus at the ankle. Part of each nerve was fixed in Flemming's solution and transverse sections stained with Kulschitsky's haematoxylin (Gutmann and Sanders, 1943). Details of measurement of fibre diameter and estimation of density were similar to those of O'Sullivan and Swallow (1968). The rest of the specimen was fixed in $10 \%$ formol saline. After staining in $1 \%$ osmium tetroxide single fibres were isolated as described by Thomas (1955).

\section{RESULTS}

CLINICAL FEATURES The patients described here are Cases 1, 4, and 5 of Garland and Patterson (1967).
The duration of exposure to acrylamide and of neurological symptoms for the three patients are shown in Table I. Two of them (J.B. and A.D.) rapidly developed severe symptoms after short exposure, but in the third patient (C.H.) abnormalities were less severe and developed slowly after longer exposure. All were recovering at the time of investigation.

TABLE I

DURATION OF EXPOSURE AND OF NEUROLOGICAL DISORDER

\begin{tabular}{|c|c|c|c|c|c|c|}
\hline \multirow{3}{*}{ Patient } & \multirow{3}{*}{$\begin{array}{l}\text { Garland } \\
\text { and } \\
\text { Patterson } \\
\text { (1967) } \\
\text { (Caseno.) }\end{array}$} & \multirow{3}{*}{ Age } & \multicolumn{4}{|c|}{ Duration (months) } \\
\hline & & & \multicolumn{2}{|c|}{ Exposure } & \multirow{2}{*}{$\begin{array}{c}\text { Since } \\
\text { end of } \\
\text { exposure }\end{array}$} & \multirow{2}{*}{ Total } \\
\hline & & & $\begin{array}{c}\text { Before } \\
\text { symptoms }\end{array}$ & $\begin{array}{c}\text { With } \\
\text { symptoms }\end{array}$ & & \\
\hline $\begin{array}{l}\text { J.B. } \\
\text { A.D. } \\
\text { C.H. }\end{array}$ & $\begin{array}{l}1 \\
4 \\
5\end{array}$ & $\begin{array}{l}19 \\
56 \\
59\end{array}$ & $\begin{array}{c}1 \\
1 \frac{1}{2} \\
18\end{array}$ & $\begin{array}{l}2 \\
\frac{1}{2} \\
2\end{array}$ & $\begin{array}{l}6 \\
8 \\
2 \frac{1}{2}\end{array}$ & $\begin{array}{c}9 \\
10 \\
22 \frac{1}{2}\end{array}$ \\
\hline
\end{tabular}

J.B. became severely disabled over the course of two months, after exposure to acrylamide for only one month before the onset of symptoms. When most severely affected he was just able to walk but fell frequently and was unable to drink from a cup. This was due to a combination of ataxia and weakness. At the time of investigation six months after removal from exposure he had improved considerably but still had some weakness of his hand muscles. He had severe bilateral foot drop and was slightly ataxic. Tendon reflexes were sluggish in the arms; ankle jerks were absent. There was no sensory abnormality.

$A . D$. became severely disabled within two weeks of the onset of symptoms, after exposure for only six weeks. At the height of the illness he was markedly ataxic, unable to walk without support and had sensory loss which caused him to burn himself without being aware of it. His symptoms slowly improved over the subsequent months. At the time of investigation, eight months later, he had mild limb 
ataxia without weakness. Tendon reflexes were all sluggish but present. There was partial loss of superficial sensation distal to the elbows and knees, vibration and position sense being normal.

C.H. had worked with acrylamide for 18 months before developing weakness and sensory symptoms in his hands and feet. These progressed slowly for two months and by the end of this time he was also ataxic. His symptoms were, however, less severe than those of the other two patients. He was recovering at the time of investigation 10 weeks later, when he still had mild distal weakness of the hands and feet, but was not ataxic. Tendon reflexes were absent. Superficial sensation was slightly impaired over the distal parts of his fingers and over his feet.

ELECTROPHYSIOLOGY The results of motor conduction studies are shown in Table II and Figure 1. Distal latency was within the control range in all instances except for the right lateral popliteal nerve of A.D. where a value of $7.5 \mathrm{msec}$ was found(control range: $4.9 \pm 0.9 \mathrm{msec}$ (Yap and Hirota, 1967). Maximal conduction velocity was normal in 11 of the 14 nerves examined. In two cases values just below the control range were recorded and in only one instance was there a marked reduction of velocity. A value of $23.8 \mathrm{~m} / \mathrm{sec}$ was found in one lateral popliteal nerve of C.H. There were only two or three surviving motor units in this nerve.

More striking than reduction in maximal conduction velocity was the dispersion of the muscle response to nerve stimulation. In many instances it was possible to identify late components in the dispersed responses; these late components appeared to be of constant waveform when the motor nerve was stimulated at different levels. After the responses to supramaximal stimulation had been recorded, stimulus intensity was varied to determine whether the late components had all-or-none responsesthat is, whether they arose from single motor units with relatively long latencies. In many instances this appeared to be the case. Examples of delayed motor

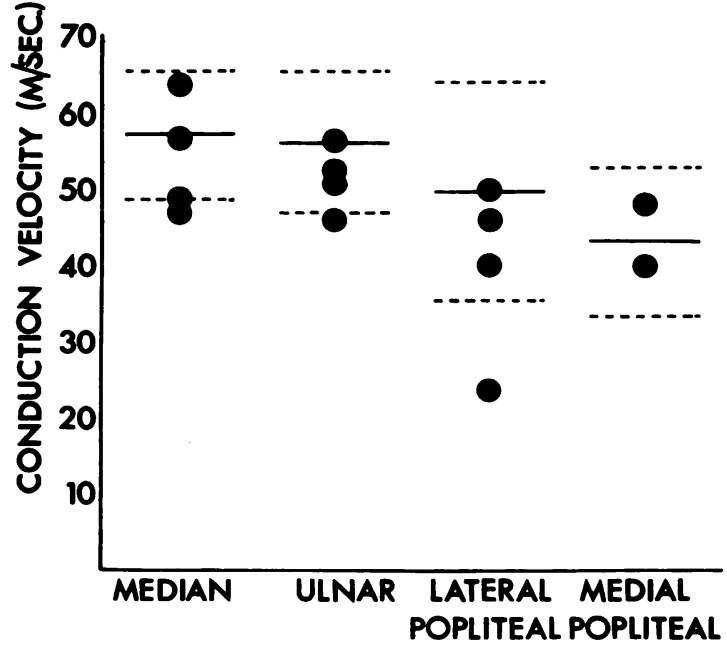

FIG. 1. Maximal motor nerve conduction velocities in the forearm and leg for the acrylamide patients. The solid lines are mean control values and dotted lines are 2 S.D. from mean obtained by Thomas, Sears, and Gilliatt (1959).

unit potentials are shown in Figures 2 and 3. In Fig. 2 the response to stimulation of the median nerve of C.H. shows a clearly recognizable late potential with stimulation at three levels in the arm, the distal latency being $17.0 \mathrm{msec}$, whereas the latency of the earliest unit to respond was $3.2 \mathrm{msec}$. Even greater dispersion of the muscle response to stimulation of the lateral popliteal nerve occurred in A.D. (Figure 3).

Conduction times over proximal segments were measured for late potentials in eight different nerves. In Fig. 4 these are compared with similar measurements for the earliest components of the response to nerve stimulation at each level. It can be seen that in all instances except one, the late motor unit potentials had distal latencies at least three times that of the early potentials, whereas proximal conduction times were only slightly longer. There was

TABLE II

MOTOR NERVE CONDUCTION VELOCITY AND DISTAL LATENCY

\begin{tabular}{|c|c|c|c|c|c|c|c|c|c|}
\hline \multirow[b]{2}{*}{ Patient } & \multicolumn{2}{|c|}{ Median nerve } & \multicolumn{2}{|c|}{ Ulnar nerve } & & \multicolumn{2}{|c|}{ Lateral popliteal } & \multicolumn{2}{|c|}{ Medial popliteal } \\
\hline & $\begin{array}{c}\text { distal } \\
\text { latency } \\
\text { (msec) }\end{array}$ & $\begin{array}{c}\text { forearm } \\
\text { velocity } \\
(\mathrm{m} / \mathrm{sec})\end{array}$ & $\begin{array}{c}\text { distal } \\
\text { latency } \\
(\text { msec)* }\end{array}$ & $\begin{array}{l}\text { forearm } \\
\text { velocity } \\
(\mathrm{m} / \mathrm{sec})\end{array}$ & & $\begin{array}{c}\text { distal } \\
\text { latency } \\
\text { (msec) }\end{array}$ & $\begin{array}{c}\text { leg } \\
\text { velocity } \\
(\mathrm{m} / \mathrm{sec})\end{array}$ & $\begin{array}{l}\text { distal } \\
\text { latency } \\
\text { (msec) }\end{array}$ & $\begin{array}{c}\text { leg } \\
\text { velocity } \\
(\mathrm{m} / \mathrm{sec})\end{array}$ \\
\hline J.B. & $4 \cdot 0$ & $56 \cdot 8$ & $3 \cdot 5$ & $52 \cdot 5$ & & absent & & $6 \cdot 2$ & $39 \cdot 8$ \\
\hline A.D. & $3 \cdot 2$ & $63 \cdot 9$ & $3 \cdot 2$ & $56 \cdot 6$ & $\begin{array}{l}\mathbf{R} \\
\mathbf{L}\end{array}$ & $\begin{array}{l}7 \cdot 5 \\
4 \cdot 2\end{array}$ & $\begin{array}{l}50 \cdot 0 \\
46.0\end{array}$ & $5 \cdot \overline{5}$ & $48 \cdot 2$ \\
\hline C.H. & $\begin{array}{l}\text { R } 3 \cdot 2 \\
\text { L } 4 \cdot 2\end{array}$ & $\begin{array}{l}47.0 \\
48.9\end{array}$ & $\begin{array}{l}4 \cdot 0 \\
5 \cdot 0\end{array}$ & $\begin{array}{l}45.9 \\
50.8\end{array}$ & & $\begin{array}{l}6 \cdot 0 \\
4 \cdot 7\end{array}$ & $\begin{array}{l}23 \cdot 8 \\
40 \cdot 0\end{array}$ & & \\
\hline
\end{tabular}

* Response recorded from first dorsal interosseus muscle. 


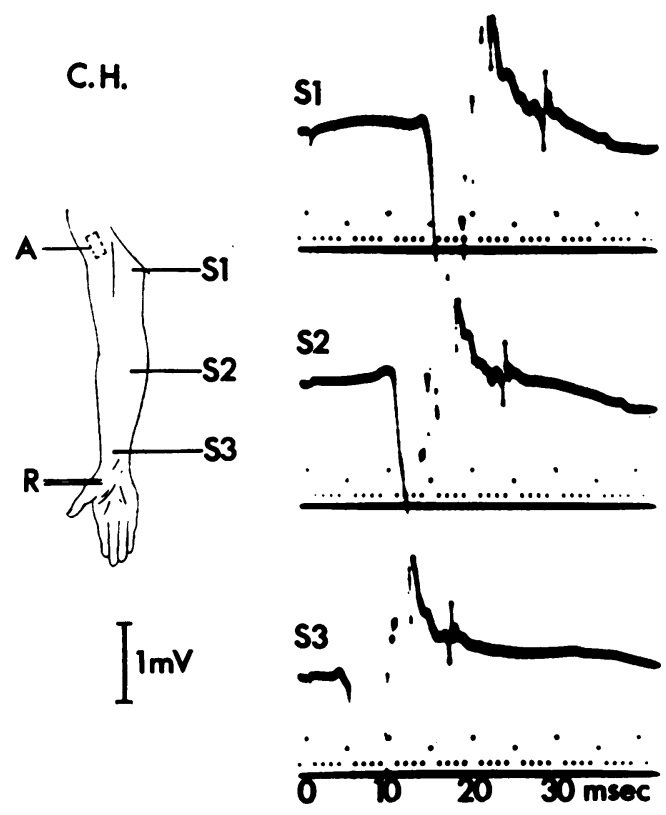

FIG. 2. Muscle action potentials recorded through a concentric needle electrode in abductor pollicis brevis in response io stimulation of median nerve at wrist, elbow, and axilla.

thus disproportionate slowing of conduction in the distal parts of these fibres. The most striking example was in the lateral popliteal nerve of A.D. (Fig. 3), the late potential having a distal latency eight times that of the early response, whereas conduction time in the leg was increased only by $30 \%$.

In the left ulnar nerve of C.H. a single motor unit potential with rather different characteristics was identified. Conduction velocity showed little change in the upper arm, but conduction time was considerably prolonged in the forearm and elbow segment as well as distal to the wrist. This indicates an abnormality extending as high as the elbow.

When sensory conduction was studied no ascending action potential could be recorded from the median nerve at the wrist with stimulation of the digital nerves of the index finger in either A.D. or J.B. A small action potential of $5 \mu \mathrm{V}$ amplitude was recorded from the median nerve of C.H.-control range 9 to $45 \mu \mathrm{V}$ (Gilliatt and Sears, 1958). These findings indicate involvement of sensory fibres in their peripheral parts.

HISTOLOGY Single fibres from the sural nerve of A.D. and C.H. were examined. Sural nerves obtained at necropsy from three control subjects aged 55 to 60

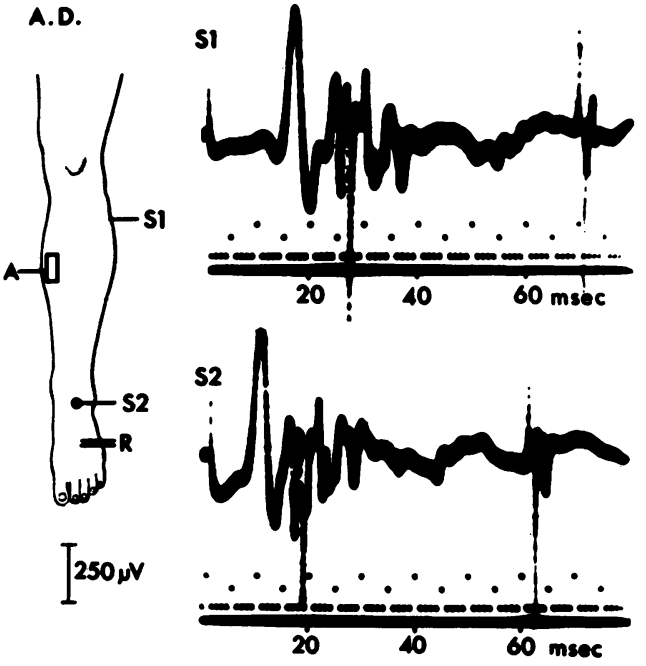

FIG. 3. Muscle action poientials recorded through a concentric needle electrode in extensor digitorum brevis in response to stimulation of anterior tibial nerve at ankle and lateral popliteal nerve at knee.

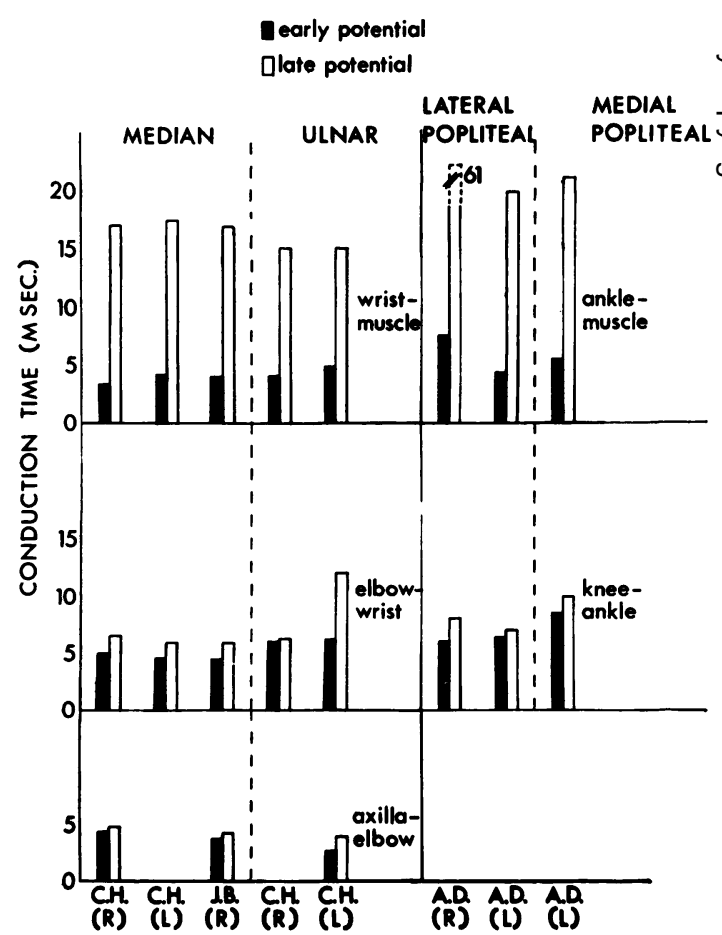

FIG. 4. Conduction times in different segments of nerve for early and late potentials. 
years were also studied for comparison. In view of the pathological changes in peripheral nerves of patients with extensive vascular disease described by Chopra and Hurwitz (1967) and Eames and Lange (1967), nerves from patients with severe atheroma were not used in the present study.

No fibres in the process of degeneration were seen in any of the control nerves or in the nerve from A.D. This patient had not been exposed to acrylamide for eight months before the biopsy was performed. C.H. had been exposed to acrylamide more recently, until two and a half months before biopsy. In his sural nerve a few fibres were seen to be undergoing degeneration, the appearance being similar to that of Wallerian degeneration.

Internodal length and fibre diameter of all the single fibres were measured and the results are shown in Fig. 5, presented as described by Fullerton, Gilliatt, Lascelles, and Morgan-Hughes (1965). A few fibres from each of the control and acrylamide nerves showed some evidence of previous segmental demyelination by the presence of internodes of irregular length along the same fibre. The incidence of this type of abnormality was no greater in the acrylamide than in the control nerves. It is interesting, however, that these three control nerves appeared to show rather more segmental demyelination than subjects of a similar age studied by Lascelles and Thomas (1966).

Regenerating fibres may be recognized by having uniformly shorter internodal lengths in relation to diameter than normal fibres (Vizoso and Young, 1948). It can be seen from Fig. 5 that some large diameter fibres from both A.D. and C.H. had shorter internodal lengths than fibres of the same diameter from the control nerves, suggesting that they had degenerated and subsequently regenerated. For example, among the single fibres isolated which did not show segmental demyelination, there were five from the nerve of A.D. and six from the nerve of C.H. with a mean diameter greater than $8 \mu$ that had a mean internodal length of less than 0.5 $\mathrm{mm}$. No large diameter fibres with such short internodes were seen in the control nerves.

Quantitative studies were carried out on transverse sections of sural nerve from C.H. The diameters of over $\mathbf{8 0 0}$ myelinated fibres were measured and density calculated. A histogram showing the distribution of fibre size is shown in Figure 6b. This

FIG. 5. Internodal length and fibre diameter for single sural nerve fibres. Each dot represents one internodal segment and segments from the same fibre are joined by a vertical line. The diameter plotted for each fibre is that of the largest segment on the fibre.
CONTROL
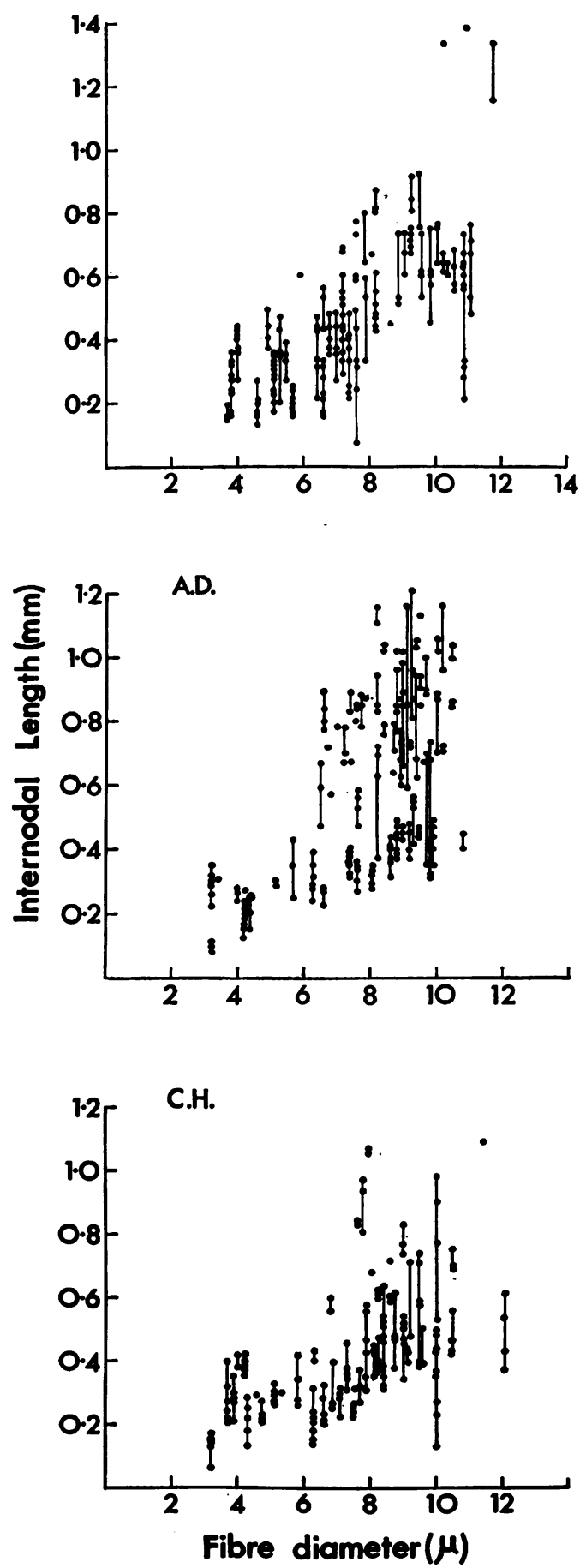


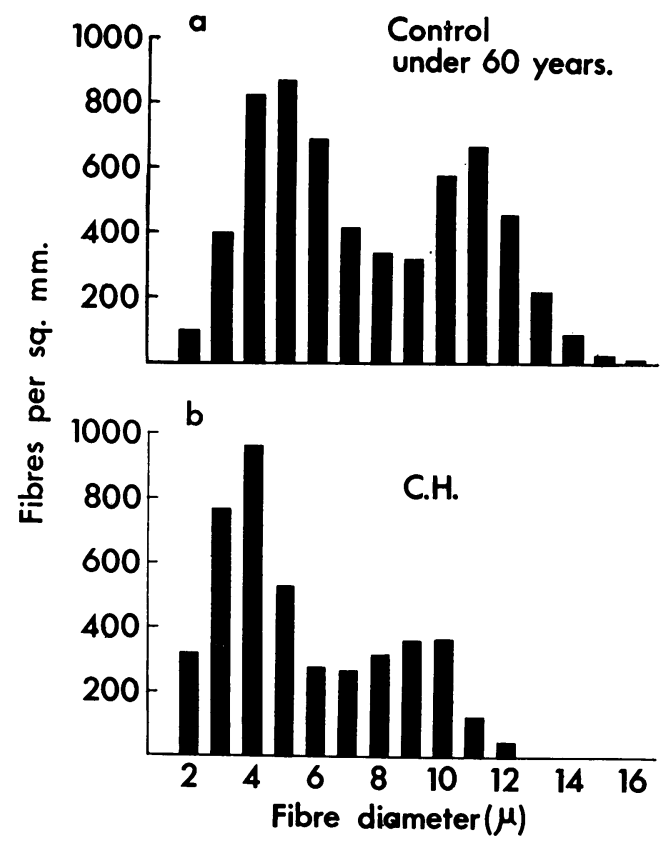

FIG. 6. Histogram of fibre diameter. $\mathrm{a}=$ control histogram for eight sural nerves calculated from data of $O$ 'Sullivan and Swallow (1968); b = acrylamide patient C.H.

may be compared with a histogram for eight control subjects under 60 years of age, calculated from the data given by O'Sullivan and Swallow (1968), and shown in Figure 6a. The distribution in both cases is bimodal, but there is some reduction in the large fibre peak in the acrylamide nerve. The overall fibre density and the densities of the small ( 2 to $8 \mu$ ) and large ( 9 to $16 \mu$ ) fibres are shown separately in Table III. Control values were again calculated from the data given by O'Sullivan and Swallow (1968). It can be seen that total and small fibre

TABLE III

TOTAL, SMALL, AND LARGE FIBRE DENSITY IN THE SURAL NERVE*

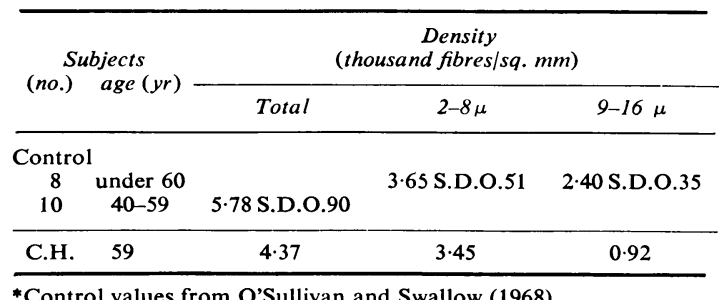

*Control values from O'Sullivan and Swallow (1968). densities are within the control range but that the large fibre density is considerably reduced.

Unfortunately, only one small bundle containing 200 fibres was present in the transverse sections from A.D. and quantitative studies are not reliable on such a small number of fibres. There appeared, however, to be no gross abnormality.

In summary, the nerve from C.H. contained a few degenerating fibres and others which were thought to have regenerated. Evidence of regeneration was also present in the nerve from A.D. In one of the patients (C.H.) a significant loss of large diameter fibres was demonstrated in transverse sections.

\section{DISCUSSION}

Acrylamide is known to be neurotoxic to many species (Kuperman, 1958; McCollister, Oyen, and Rowe, 1964). Pathological changes in peripheral nerves of rats fed with acrylamide in their diet were described by Fullerton and Barnes (1966). These consisted of a dying-back process with fibre degeneration affecting first and most severely the distal ends of the longest fibres. No segmental demyelination was found in this species. More recently similar pathology has been demonstrated in baboons, but in this species paranodal demyelination was also seen (Hopkins and Gilliatt, 1967 ; Hopkins, in preparation).

Peripheral nerve conduction was studied in both these species. In severely paralysed rats, maximal motor conduction velocity was reduced by $20 \%$ and? in baboons there was often a reduction of 30 to $40 \%$. In the present study changes in maximal velocity were slight. These changes in maximal velocity in both man and animals are substantially less than those which may occur when segmental demyelination is present (Gilliatt, 1966; Morgan-Hughes, 1968). As far as sensory nerve conduction is concerned, Hopkins and Gilliatt (1967) found that action potentials disappeared in baboons during acrylamide poisoning. This finding is comparable with the observations on the patients reported here.

An interesting feature of the present study was the marked dispersion of the muscle responses to nerve stimulation. This appeared to be due to delayed conduction in the distal parts of some of the motor fibres, others being unaffected. This phenomenon is most likely to be an indication of regeneration, since conduction velocity is known to be as low as $5 \%$ of normal in the earliest stages of regeneration (Hodes, Larrabee, and German, 1948). If this be the correct explanation, then regeneration appears to be confined to the distal parts of the fibres. This would be expected in the early stages of recovery from a dying-back disease. Rather similar electrical 
findings have been seen during recovery from tri-ortho-cresyl phosphate neuropathy in baboons (J.E.C. Hern, personal communication).

It seems unlikely that the late muscle potentials were merely parts of motor units with lengthened duration due to collateral sprouting, since they appeared to have different thresholds from the early part of the muscle action potential. However, it is difficult to eliminate this possibility entirely. For example, Fullerton and Gilliatt (1965) demonstrated that axon branching could occur in peripheral nerve lesions in man and that the branches might terminate in widely separate parts of the muscle, so that the two components could not be recorded through a single coaxial needle electrode.

One other possible interpretation is that pressure might have produced localized nerve damage. In some conditions pathological nerves are known to be unduly susceptible to pressure, for example in diabetes (Mulder, Lambert, Bastron, and Sprague, 1961), some familial neuropathies (Earl, Fullerton, Wakefield, and Schutta, 1964), and experimental diphtheritic neuropathy (Hopkins and MorganHughes, 1967). Compression in the carpal tunnel could explain the distal slowing in the median nerves. The finding that slowing extends as high as the elbow in one ulnar nerve of C.H. might add some support to this explanation, since pressure lesions at the elbow are common. However, in all the other fibres studied, including the other ulnar nerve of C.H., marked delay was confined to their distal parts regardless of whether or not these are common sites for pressure to occur. This explanation thus seems unlikely.

It is interesting that some fibres were found in the nerve biopsy specimen from C.H. with large diameters and short internodal lengths. Despite the fact that the biopsy was taken only two-and-a-half months after he stopped work, this suggests that regeneration was well advanced. It seems likely that regeneration was occurring while exposure continued and even before the patient had developed symptoms two months previously. In rat nerves Fullerton and Barnes (1966) also found evidence of regeneration while the animals continued on a low dose of acrylamide in their diet.

\section{SUMMARY}

Maximal motor nerve conduction velocity in three patients recovering from acrylamide neuropathy was normal or only slightly reduced, except in one nerve. The muscle response to nerve stimulation was usually dispersed and potentials with markedly prolonged distal latencies were found. It is suggested that the slow conduction is due to degeneration followed by regeneration of the distal parts of the fibres. Sensory nerve action potentials were reduced in amplitude or absent.

Pathological examination of sural nerves from two patients showed that segmental demyelination was no more common than in control nerves. Degenerating fibres were found in the patient most recently exposed to acrylamide and evidence of regeneration was found in both nerves. Correlation with the clinical course in one patient suggested that degeneration and regeneration began before symptoms developed.

I would like to thank Dr. J. Phemister and Dr. T. O. Garland for allowing me to investigate their patients, Mr. A. G. L. Corkill for carrying out the sural nerve biopsies, Miss G. Brann for histological assistance, and Professor R. W. Gilliatt for his helpful criticism.

\section{REFERENCES}

Auld, R. B., and Bedwell, S. F. (1967). Peripheral neuropathy with sympathetic overactivity from industrial contact with acrylamide. Canad. med. Ass. J., 96, 652-654.

Chopra, J. S., and Hurwitz, L. J. (1967). Internodal length of sural nerve fibres in chronic occlusive vascular disease. J. Neurol. Neurosurg. Psychiat., 30, 207-214.

Dawson, G. D. (1956). The relative excitability and conduction velocity of sensory and motor nerve fibres in man. J. Physiol. (Lond.), 131, 436-451.

Eames, R. A., and Lange, L. S. (1967). Clinical and pathological study of ischaemic neuropathy. J. Neurol. Neurosurg.Psychiat., 30, 215-226.

Earl, C. J., Fullerton, P. M., Wakefield, G. S., and Schutta, H. S. (1964). Hereditary neuropathy, with liability to pressure palsies. A clinical and electrophysiological study of four families. Quart. J. Med., 33, 481-498.

Fujita, A., Shibata, M., Kato, H., Amomi, Y., Itomi, K., Sujuki, K., Nakajawa, T., and Takahashi, T. (1960). Clinical observations on acrylamide poisoning. Nippon Iji Shinpo, 1869, 37.

Fullerton, P. M., and Barnes, J. M. (1966). Peripheral neuropathy in rats produced by acrylamide. Brit. J. industr. Med., 23, 210-221.

, and Gilliatt, R. W. (1965). Axon reflexes in human motor nerve fibres. J. Neurol. Nerusorug. Psychiat., 28, 1-11.

- - , Lascelles, R. G., and Morgan-Hughes, J. A. (1965). The relation between fibre diameter and internodal length in chronic neuropathy. J. Physiol. (Lond.), 178, 26-28P.

Garland, T. O., and Patterson, M. W. H. (1967). Six cases of acrylamide poisoning. Brit. med. J., 4, 134-138.

Gilliatt, R. W. (1966). Nerve conduction in human and experimental neuropathies. Proc. roy. Soc. Med., 59, 989-993.

patients with peripheral nerve lesions. J. Neurol. Neurosurg. Psychiat., 21, 109-118.

Gutmann, E., and Sanders, F. K. (1943). Recovery of fibre numbers and diameters in the regeneration of peripheral nerves. $J$. Physiol. (Lond.), 101, 489-518.

Hodes, R., Larrabee, M. G., and German, W. (1948). The human electromyogram in response to nerve stimulation and the conduction velocity of motor axons. Studies on normal and injured peripheral nerves. Arch. Neurol. Psychiat (Chic.), 60, 340-365.

Hopkins, A. P. (In preparation). Experimental Neuropathy in the Baboon. M.D. Thesis, London University.

_- and Gilliatt, R. W. (1967). Acrylamide poisoning. Brit. med. J., 4, 417.

_- and Morgan-Hughes, J. A. (1967). The effect of local pressure in diphtheritic neuropathy. J. Physiol. (Lond.), 189, 81-82P.

Kuperman, A. S. (1958). Effects of acrylamide on the central nervous system of the cat. J. Pharmacol. exp. Ther., 123, 180-192.

Lascelles, R. G., and Thomas, P. K. (1966). Changes due to age in internodal length in the sural nerve in man. J. Neurol. Neurosurg. Psychiat., 29, 40-44. 
McCollister, D. D., Oyen, F., and Rowe, V. K. (1964). Toxicology of acrylamide. Toxicol. appl. Pharmacol., 6, 172-181.

Morgan-Hughes, J. A. (1968). Experimental diphtheritic neuropathy. A pathological and electrophysiological study. J. neurol. Sci., 7, 157-175.

Mulder, D. W., Lambert, E. H., Bastron, J. A., and Sprague, R. G. (1961). The neuropathies associated with diabetes mellitus. A clinical and electromyographic study of 103 unselected diabetic patients. Neurology (Minneap.), 11, 275-284.

O'Sullivan, D. J., and Swallow, M. (1968). The fibre size and content of the radial and sural nerves. J. Neurol. Neurosurg. Psychiat., $31,464-470$.
Thomas, P. K. (1955). Growth changes in the myelin sheath of peripheral nerve fibres in fishes. Proc. roy. Soc. B., 143, 380-391.

-, Sears, T. A., and Gilliatt, R. W. (1959). The range of conduction velocity in normal motor nerve fibres to the small muscles of the hand and foot. J. Neurol. Neurosurg. Psychiat., 22, 175-181.

Vizoso, A. D., and Young, J. Z. (1948). Internode length and fibre diameter in developing and regenerating nerves. $J$. Anat. (Lond.), 82, 110-134.

Yap, C. P., and Hirota, T. (1967). Sciatic nerve motor conduction velocity study. J. Neurol. Neurosurg. Psychiat., 30, 233-239. 